\title{
Faktor-Faktor yang Memengaruhi Gangguan Perilaku pada Anak Epilepsi
}

\author{
Alvi Lavina, Dwi Putro Widodo, Surastusi Nurdadi, Bambang Tridjaja \\ Departemen Ilmu Kesehatan Anak Fakultas Kedokteran Universitas Indonesia/RS Dr. Cipto \\ Mangunkusumo, Jakarta
}

\begin{abstract}
Latar belakang. Anak epilepsi memiliki prevalensi gangguan perilaku yang tinggi dan dapat menyebabkan dampak psikososial. Sejauh ini, di Indonesia, belum ditemukan studi yang meneliti gangguan perilaku pada anak epilepsi serta faktor-faktor yang berhubungan.

Tujuan. Mengetahui proporsi dan jenis gangguan perilaku anak epilepsi berdasarkan child behavior checklist (CBCL) dan hubungan antara usia awitan kejang, frekuensi kejang, durasi epilepsi, obat anti epilepsi, tingkat sosial ekonomi, dan pendidikan orangtua, dengan gangguan perilaku pada anak epilepsi, serta adaptasi keluarga dalam menghadapi anak epilepsi.

Metode. Penelitian potong lintang di Klinik Neurologi Anak FKUI RSCM. Skrining gangguan perilaku dengan kuesioner CBCL dilakukan pada 30 anak epilepsi tanpa defisit neurologis dan disabilitas intelektual. Studi kualitatif untuk menilai adaptasi keluarga dalam menghadapi anak epilepsi.

Hasil. Terdapat 3 dari 30 anak epilepsi yang mengalami gangguan perilaku dengan jenis gangguan perilaku eksternalisasi (perilaku melanggar aturan dan agresif), masalah sosial, dan gangguan pemusatan perhatian. Faktor usia awitan kejang $(\mathrm{p}=0,280)$, frekuensi kejang ( $\mathrm{p}=0,007$; RP 0,036; IK95\% 0,005-0,245), durasi epilepsi ( $\mathrm{p}=1,000)$, obat anti epilepsi ( $\mathrm{p}=0,020$; RP 0,019; IK95\% 0,001-0,437), tingkat sosial ekonomi $(\mathrm{p}=0,251)$, dan pendidikan orangtua $(\mathrm{p}=1,000)$, tidak berisiko meningkatkan gangguan perilaku. Terdapat sikap dan reaksi, serta persepsi dan stigma orangtua yang negatif dalam menghadapi anak epilepsi yang mengalami gangguan perilaku. Terdapat masalah keluarga sejak anak mengalami epilepsi dan gangguan perilaku. Orangtua tidak dapat menerapkan pola asuh displin dan kemandirian pada anak dengan gangguan perilaku.

Kesimpulan. Proporsi gangguan perilaku pada anak epilepsi tanpa defisit neurologis dan disabilitas intelektual tidak tinggi. Tidak terdapat faktor yang memengaruhi gangguan perilaku. Adaptasi keluarga baik dalam menghadapi anak epilepsi tanpa gangguan perilaku, dibandingkan dengan keluarga anak epilepsi yang mengalami gangguan perilaku. Sari Pediatri 2015;16(6):409-15.
\end{abstract}

Kata kunci: epilepsi, gangguan perilaku, faktor yang berhubungan, adaptasi keluarga

\footnotetext{
Alamat korespondensi:

Dr. Alvi Lavina, Sp.A. Departemen Ilmu Kesehatan Anak Fakultas Kedokteran Universitas Indonesia/RS Dr. Cipto Mangunkusumo, Jakarta E-mail:alvi_lavina@idai.or.id,alvi_lavina@yahoo.com
}

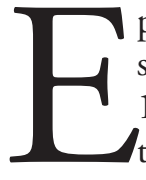
pilepsi merupakan masalah neurologis paling sering ditemukan di dunia, sekitar 0,5\%$1 \%$ pada populasi anak. ${ }^{1,2}$ Di Indonesia terdapat 700.000-1.400.000 kasus epilepsi 
dengan pertambahan 70.000 kasus baru per tahun, dan diperkirakan 40\%-50\% terjadi pada anak. ${ }^{3}$ Penderita epilepsi mempunyai gangguan perilaku lebih besar dibandingkan penyakit kronis lain, seperti diabetes, asma, penyakit jantung, dan artritis reumatoid, ${ }^{4-6}$ atau pada anak sehat. ${ }^{7}$ Suatu studi melaporkan gangguan perilaku pada populasi anak normal mencapai $6,6 \%$, anak dengan penyakit kronis non-neurologik 11,6\%, epilepsi idiopatik $28,6 \%$, dan pada epilepsi simtomatik $58,3 \% .^{8}$

Beberapa studi pada epilepsi kronik ditemukan usia awitan kejang yang lebih muda, tipe/etiologi epilepsi simtomatik, frekuensi kejang yang tidak terkontrol, durasi epilepsi yang lama, politerapi, disabilitas intelektual, adaptasi keluarga yang buruk, tingkat sosial ekonomi yang rendah, dan tingkat pendidikan orangtua yang rendah dapat meningkatkan gangguan perilaku ${ }^{9-15}$ Beberapa studi juga menemukan prevalensi gangguan perilaku yang tinggi pada anak epilepsi yang baru terdiagnosis. ${ }^{16-19}$

Gangguan perilaku jarang diperhatikan oleh tenaga kesehatan dan keluarga pasien. Akibatnya, anak epilepsi dengan gangguan perilaku yang tidak mendapat terapi cenderung mengalami dampak psikososial saat dewasa, yaitu tidak menyelesaikan sekolah, tidak menikah, tidak bekerja, atau bekerja dengan upah yang rendah, dan mempunyai tingkat sosial ekonomi yang rendah. ${ }^{20}$

Adaptasi keluarga yang buruk juga dapat membentuk perilaku anak yang buruk. Adaptasi keluarga yang buruk, meliputi sikap dan reaksi negatif orangtua menghadapi kondisi anak, persepsi dan stigma orangtua yang tidak baik mengenai epilepsi, sikap anak yang buruk menghadapi epilepsi, masalah dalam keluarga, dan pola asuh orangtua dalam menerapkan displin dan kemandirian pada anak yang tidak tepat. Tata laksana epilepsi secara menyeluruh itu penting, tidak hanya melibatkan aspek medis, tetapi juga non medis yaitu memberikan psikoedukasi/konseling pada anak dan anggota keluarga. ${ }^{22-25}$

\section{Metode}

Peneliti melakukan studi kuantitatif dengan uji potong lintang untuk mengetahui proporsi dan jenis gangguan perilaku, serta faktor yang memengaruhi. Kemudian dilanjutkan dengan studi kualitatif untuk menilai kemampuan adaptasi keluarga dalam menghadapi anak epilepsi. Kriteria inklusi adalah pasien berobat jalan di
Divisi Neurologi Departemen IKA FKUI-RSCM yang memenuhi kriteria epilepsi minimal 6 bulan setelah diagnosis, berusia 6-12 tahun, tidak terdapat defisit neurologis, dan disabilitas intelektual menggunakan coloured progressive matrices. Kriteria eksklusi adalah pasien menderita penyakit kronik dan memiliki orangtua memiliki gangguan mental.

Variabel kejang usia awitan kejang dibedakan menjadi 3 grup, yaitu awitan kejang sebelum usia 5 tahun, antara 5-10 tahun, dan di atas 10 tahun. Tipe kejang dibagi menjadi 3 grup, yaitu kejang parsial, umum, dan parsial dengan sekunder umum. Frekuensi kejang diklasifikasi menjadi 3 grup, yaitu tidak ada kejang (minimal 6 bulan), frekuensi kejang $<6$ kali dalam 6 bulan, dan frekuensi kejang $\geq 6$ kali dalam 6 bulan. Durasi epilepsi dibagi menjadi 2 grup, yaitu durasi epilepsi kurang $<2$ tahun dan $\geq 2$ tahun. Obat anti epilepsi diklasifikasi menjadi 3 grup, yaitu menggunakan 1 jenis OAE (selain fenobarbital), menggunakan lebih dari 1 jenis OAE (selain fenobarbital), dan menggunakan fenobarbital.

Klasifikasi gangguan perilaku menurut CBCL jika memenuhi salah satu kriteria yang terdapat dalam format problem scale, yaitu jumlah skor tiap skala sindrom dalam lebih dari persentil 98 , skor internalisasi lebih dari persentil 87, skor eksternalisasi lebih dari persentil 87, dan skor total lebih dari persentil 87. Studi kualitatif mengenai adaptasi keluarga, meliputi sikap dan reaksi negatif orangtua dalam menghadapi diagnosis epilepsi. Persepsi dan stigma orangtua terhadap epilepsi. Perilaku anak menghadapi epilepsi. Masalah keluarga, seperti perceraian, stres dalam keluarga, dan gangguan psikologi pada anggota keluarga yang lain. Ketidakmampuan orangtua dalam menerapkan displin dan kemandirian anak.

Semua data kuantitatif diolah ke dalam data base komputer menggunakan program SPSS versi 20.0. Analisis bivariat dilakukan dengan uji hipotesis Fisher karena pada syarat uji Kai kuadrat tidak terpenuhi. Peneliti melakukan transkrip dan analisis data kualitatif yang diperoleh dari wawancara pada orangtua subjek. Penelitian telah mendapatkan persetujuan etik penelitian dari Komisi Etik Penelitian FKUI.

\section{Hasil}

Karakteristik kejang pada subjek, sebagian besar usia awitan kejang adalah usia 5-10 tahun (25 subjek), 
Tabel 1. Karakteristik subjek penelitian

\begin{tabular}{lc}
\hline Variabel & Jumlah $(\mathrm{n}=30)$ \\
\hline Usia (tahun; (rerata, range) & 9 (6 tahun sd 12 tahun 4 bulan) \\
Jenis kelamin & 10 \\
Perempuan & 20 \\
Lelaki & 3 \\
Sosial Ekonomi Keluarga Berdasarkan Pengeluaran Keluarga per Kapita Sebulan & 2 \\
(Rupiah) & 0 \\
500.000-599.999 & 3 \\
$600.000-699.999$ & 2 \\
$700.000-799.999$ & 20 \\
$800.000-899.999$ & 4 \\
$900.000-999.999$ & 14 \\
$>1.000 .000$ & 12 \\
Pendidikan orangtua & 0 \\
Dasar & 30 \\
Menengah & \\
Tinggi & 2 \\
Yayat gangguan mental pada keluarga & 28 \\
Tidak & 2 \\
Oruktur keluarga & 11 \\
Keluarga inti & 11 \\
Hasil potensi kognitif & \\
Rata-rata & \\
Rata-rata tinggi & \\
Di atas rata-rata & \\
\hline
\end{tabular}

Tabel 2. Karakteristik klinis kejang pada 30 anak epilepsi

\begin{tabular}{lc}
\hline Usia awitan kejang (tahun) & 2 \\
$<5$ & 25 \\
$5-10$ & 3 \\
$>10$ & 4 \\
Tipe kejang & 21 \\
$\quad$ Parsial & 5 \\
$\quad$ Umum & 19 \\
$\quad$ Parsial dengan sekunder umum & 9 \\
Frekuensi kejang & 2 \\
$\quad$ Tidak ada kejang dalam 6 bulan & 26 \\
$\quad<6$ kali dalam 6 bulan & 2 \\
$\geq 6$ kali dalam 6 bulan & 2 \\
Frekuensi kejang sebelum diagnosis (kali sehari) & \\
$1-4$ & 20 \\
$5-9$ & 10 \\
$\geq 10$ & 26 \\
Durasi epilepsi (tahun) & 3 \\
$\quad<2$ & 2 \\
Obat anti epilepsi & 1 \\
1 obat & 2 \\
$>1$ obat & 2 \\
Fenobarbital & 2 \\
\hline
\end{tabular}


dengan tipe kejang umum (21 subjek). Umumnya, frekuensi kejang rendah dan durasi mengalami epilepsi pendek, yaitu subjek tidak mengalami kejang dalam 6 bulan (19 subjek), frekuensi kejang sebelum diagnosis 1-4 kali sehari (26 subjek), dan durasi mengalami epilepsi kurang dari 2 tahun (20). Sebagian besar subjek mengkonsumsi satu obat (26 subjek) (Tabel 1 dan 2).

Faktor-faktor yang berhubungan dengan gangguan perilaku dinilai dari kKeenam variabel tidak memenuhi syarat uji Kai kuadrat sehingga peneliti melakukan penggabungan sel dan menggunakan uji Fisher (Tabel 2). awal diagnosis, atau setelah pengobatan. Child behavior checklist sebagai alat untuk menilai gangguan perilaku anak, hanya mengandalkan pengamatan orangtua sehingga perlu dilakukan observasi pada anak dan keluarga agar didapatkan hasil yang lebih akurat. ${ }^{24,25}$ Kekuatan penelitian ini adalah mencantumkan subjek dengan kecerdasan rata-rata ke atas sebagai kriteria inklusi sehingga mengurangi bias gangguan perilaku yang terjadi pada anak akibat disabilitas intelektual.

Terdapat 3 anak mengalami gangguan perilaku dari 30 anak epilepsi tanpa defisit neurologis dan disabilitas intelektual. Proporsi gangguan perilaku pada studi ini

Tabel 3. Karakteristik pasien yang mengalami gangguan perilaku dengan tidak mengalami gangguan perilaku

\begin{tabular}{|c|c|c|c|c|c|}
\hline Karakteristik & $\begin{array}{c}\text { Gangguan } \\
\text { perilaku }(+) \\
n=3\end{array}$ & $\begin{array}{c}\text { Gangguan } \\
\text { perilaku (-) } \\
\mathrm{n}=27\end{array}$ & $\mathrm{RP}$ & $\mathrm{p}$ & IK95\% \\
\hline \multicolumn{6}{|c|}{$\begin{array}{l}\text { Pengeluaran keluarga per kapita sebulan } \\
\text { (rupiah) }\end{array}$} \\
\hline$<1.000 .000$ & 2 & 8 & 4,750 & 0,251 & $0,375-60,145$ \\
\hline$\geq 1.000 .000$ & 1 & 19 & & & \\
\hline \multicolumn{6}{|c|}{ Tingkat pendidikan orangtua } \\
\hline Dasar - menengah & 2 & 16 & 1,375 & 1,000 & $0,111-17,093$ \\
\hline Tinggi & 1 & 11 & & & \\
\hline \multicolumn{6}{|c|}{ Usia awitan kejang (tahun) } \\
\hline$<10$ & 2 & 25 & 0,160 & 0,280 & $0,010-2,630$ \\
\hline$\geq 10$ & 1 & 2 & & & \\
\hline \multicolumn{6}{|c|}{ Frekuensi kejang (kali dalam 6 bulan) } \\
\hline$\geq 6$ & 2 & 0 & 0,036 & $0,007^{*}$ & $0,005-0,245$ \\
\hline$<6$ & 1 & 27 & & & \\
\hline \multicolumn{6}{|l|}{ Durasi epilepsi (tahun) } \\
\hline$\geq 2$ & 1 & 9 & 1,000 & 1,000 & $0,008-12,557$ \\
\hline$<2$ & 2 & 18 & & & \\
\hline \multicolumn{6}{|l|}{ Obat anti epilepsi } \\
\hline$>1$ & 2 & 1 & 0,019 & $0,020^{*}$ & $0,001-0,437$ \\
\hline 1 & 1 & 26 & & & \\
\hline
\end{tabular}

*Uji Fisher $\mathrm{p}<0,05$ bermakna secara statistik

\section{Pembahasan}

Proporsi gangguan perilaku pada studi ini lebih kecil dibandingkan dengan penelitian sebelumnya karena jumlah subjek yang lebih kecil. Studi ini menggunakan desain uji potong lintang, yaitu observasi dan pengukuran pada satu saat tertentu sehingga dapat terjadi recall bias saat orangtua menjawab kuesioner $\mathrm{CBCL}$, misalnya apakah gangguan perilaku timbul saat lebih rendah dibandingkan studi sebelumnya, yaitu 22\%-26\% pada anak epilepsi idiopatik. ${ }^{9-11}$ Terdapat beberapa kemungkinan proporsi penelitian ini rendah. Pertama, jumlah subjek lebih kecil dibandingkan dengan studi sebelumnya sehingga mungkin tidak menggambarkan kondisi sebenarnya. Kedua, subjek yang diikutsertakan memiliki kecerdasan rata-rata ke atas-studi-studi sebelumnya tidak memasukkan tes intelektual pada kriteria inklusi. ${ }^{9-11}$ Ketiga, subjek 
penelitian ini mempunyai frekuensi kejang yang rendah sebelum diagnosis dan terkontrol baik dengan obat anti epilepsi. Austin $\mathrm{dkk}^{10}$ melaporkan bahwa gangguan perilaku pada anak epilepsi kejang berulang lebih besar dibandingkan anak epilepsi kejang terkontrol. Keempat, peneliti menduga adaptasi keluarga yang baik pada studi ini menyebabkan proporsi gangguan perilaku yang lebih rendah dibandingkan penelitian sebelumnya.

Jenis gangguan perilaku adalah gangguan eksternalisasi, masalah sosial, dan pemusatan perhatian. Hasil tersebut serupa dengan laporan Freilinger $\mathrm{dkk}^{11}$ yang menemukan $14,8 \%$ gangguan eksternalisasi, $13 \%$ masalah sosial, dan $11,2 \%$ gangguan pemusatan perhatian, dari 108 anak yang menderita epilepsi idiopatik.

Tingkat sosial ekonomi dan pendidikan yang rendah mengakibatkan adaptasi keluarga buruk sehingga membentuk perilaku yang buruk pada anak epilepsi. ${ }^{26,27}$ Hubungan antara tingkat sosial ekonomi dan pendidikan orangtua dengan gangguan perilaku juga tidak ditemukan. Hal tersebut diduga karena sebagian besar keluarga pada penelitian ini memiliki tingkat sosial ekonomi dan pendidikan menengah ke atas. Hasil serupa ditemukan pada survei oleh McDermot $\mathrm{dkk}^{6}$ yang melaporkan bahwa faktor sosial demografi tidak memengaruhi gangguan perilaku pada anak epilepsi.

Kami tidak mendapatkan hubungan antara gangguan perilaku dengan usia awitan kejang. Kami menduga karena sebagian besar usia awitan kejang subjek $>5$ tahun. Jayashree $\mathrm{dkk}^{28}$ menemukan pasien dengan usia awitan kejang $<5$ tahun mengalami gangguan perilaku lebih besar dibandingkan anak usia awitan kejang $>5$ tahun. Sebaliknya, Oostrom $\mathrm{dkk}^{19}$ juga tidak menemukan hubungan gangguan perilaku dengan usia awitan kejang pada anak epilepsi idiopatik.

Datta $\mathrm{dkk}^{29}$ menemukan gangguan perilaku lebih besar pada anak dengan durasi epilepsi lebih dari 3 tahun dibandingkan dengan yang kurang dari 3 tahun. Kami tidak menemukan hubungan antara durasi kejang dengan gangguan perilaku. Hal tersebut mungkin disebabkan sebagian besar subjek menderita epilepsi kurang dari 2 tahun. Pada sisi lain, terdapat hubungan antara frekuensi kejang dengan gangguan perilaku. Namun, rasio prevalensi menunjukkan bahwa frekuensi kejang yang tidak terkontrol tidak berisiko meningkatkan gangguan perilaku. Hasil serupa ditemukan Oostrom dkk, ${ }^{18}$ dan Freilinger dkk, ${ }^{11}$ yang tidak menemukan hubungan antara frekuensi kejang dan durasi epilepsi dengan gangguan perilaku. Sebagian ahli berpendapat bahwa kejang itu sendiri tidak menyebabkan gangguan perilaku, tetapi adanya suatu insult neurologi yang menyebabkan kejang dan gangguan perilaku. ${ }^{16,17}$

Kami mendapatkan hubungan antara OAE dengan gangguan perilaku. Akan tetapi, rasio prevalensi menunjukkan bahwa politerapi tidak berisiko meningkatkan gangguan perilaku. Hasil serupa ditemukan pada studi oleh Oostrom $\mathrm{dkk}^{18}$ yang tidak menemukan hubungan antara obat anti epilepsi dengan gangguan perilaku. Masih menjadi perdebatan para ahli bahwa obat anti epilepsi dapat menyebabkan gangguan perilaku karena banyak faktor yang memengaruhinya seperti lesi serebral, usia awitan kejang, etiologi kejang, frekuensi kejang, dan durasi epilepsi. . $^{30,31}$

Pada subjek yang mengalami gangguan perilaku, orangtua mengeluh perilaku anak berubah sejak menderita epilepsi. Anak menunjukkan sikap agresif, yaitu sering membantah, menuntut banyak perhatian, tidak patuh di rumah, sering terlibat perkelahian, menyerang fisik orang, keras kepala, sering jahil, dan mudah marah/mengamuk. Kami menduga gangguan perilaku yang timbul bukan karena adaptasi keluarga yang buruk dalam menghadapi anak epilepsi, melainkan gelombang epileptiform pada susunan saraf pusat yang menyebabkan kejang dan gangguan perilaku pada anak. ${ }^{18}$

Pada studi ini, keluarga belum dapat beradaptasi dengan baik yaitu terdapat sikap dan reaksi negatif orangtua, persepsi dan stigma orangtua yang negatif mengenai epilepsi, anggota keluarga sedih/stres menghadapi kondisi anak, serta pola asuh orangtua yang tidak tepat dalam menerapkan displin dan kemandirian. Orangtua sedih, stres, marah, bingungbahkan terkadang menyalahkan Tuhan-dalam menghadapi perilaku anak. Terdapat satu keluarga yang tidak menerima diagnosis bahwa anaknya epilepsi. Alasan mereka belum dapat menerima diagnosis anak tersebut karena persepsi dan stigma orangtua yang negatif terhadap epilepsi, yaitu pada penderita epilepsi terdapat disabilitas fisik dan intelektual. Studi oleh Oostrom $\mathrm{dkk}^{25}$ melaporkan bahwa orangtua dengan anak epilepsi yang memiliki gejala epilepsi ringan beradaptasi lebih baik dibandingkan orangtua dengan anak epilepsi yang mempunyai gejala berat. Orangtua dan anggota keluarga sedih dan stres menghadapi 
kondisi anak dengan gangguan perilaku. Orangtua tidak dapat menerapkan displin/kemandirian yang sama pada anak seperti sebelum menderita epilepsi karena perubahan sikap anak.

Gangguan perilaku yang terjadi bukan akibat adaptasi keluarga yang buruk dalam menghadapi anak epilepsi karena gangguan perilaku timbul sejak anak menderita kejang. Akan tetapi, jika keluarga tidak dapat beradaptasi dengan baik maka gangguan perilaku anak semakin memburuk. ${ }^{25}$ Tata laksana epilepsi secara menyeluruh meliputi aspek medis dan non medis. Dokter dan tenaga kesehatan mental dapat memberikan konseling pada keluarga secara bersama-sama. ${ }^{24-25}$

Sikap anak epilepsi tanpa gangguan perilaku baik, mereka dapat beradaptasi menghadapi penyakitnya, mau minum obat teratur, percaya diri, tidak menarik diri, tidak cemas/depresi, dan mempunyai hubungan baik dengan teman-temannya. Kami menduga adaptasi anak yang baik terjadi karena kejang yang cepat terkontrol sehingga anak tidak merasa khawatir kejang akan timbul kembali saat aktivitas di sekolah maupun di luar sekolah. Pada studi ini, sebagian besar anak belum mengalami fase pubertas, dengan rata-rata usia subjek adalah 9 tahun, dan anak dapat beradaptasi dengan baik. Satu studi menyebutkan anak epilepsi idiopatik yang berusia lebih muda $(8,5 \pm 2,3)$ tahun, lebih dapat beradaptasi dengan baik dibandingkan anak usia lebih tua $(11,5 \pm 2,8)$ tahun. ${ }^{25} \mathrm{Hal}$ tersebut mungkin berkaitan dengan fase anak, yaitu pada usia 11-14 tahun anak mengalami pubertas, perbedaan dalam dirinya, seperti epilepsi dapat menyebabkan anak tidak percaya diri dan menarik diri.

Adaptasi keluarga cukup baik dalam menghadapi anak epilepsi tanpa gangguan perilaku dibandingkan dengan yang mengalami gangguan perilaku. Mereka menerima diagnosis anak, tidak sedih/khawatir yang berlebihan, dan membawa anak berobat secara teratur. Pengetahuan epilepsi orangtua cukup baik, mereka mengerti bahwa kejang dapat dikontrol dengan obat anti epilepsi. Namun demikan, sebagian pengetahuan mereka terhadap gejala epilepsi belum benar. Tenaga medis harus memberikan konseling secara berkala terhadap orangtua dan keluarga, agar pengetahuan orangtua dan keluarga mengenai epilepsi baik, serta meningkatkan luaran epilepsi. ${ }^{23-25}$ Kami tidak menemukan masalah keluarga pada subjek yang tidak mengalami gangguan perilaku. Saat awal anak mengalami kejang orangtua cemas dan khawatir. Kecemasan orangtua berkurang setelah kejang anak terkontrol dan anak tidak mengalami penurunan prestasi akademik. Sebagian besar orangtua tidak cemas berlebihan sehingga tidak membatasi aktivitas anak dan menerapkan pola asuh displin/kemandirian yang tepat, tetapi terdapat orangtua yang menyediakan fasilitas gadget di rumah, dan membatasi aktivitas anak di luar rumah. Tindakan tersebut dapat menurunkan kemampuan sosial dan pengembangan moral anak (mengikuti aturan, penyelesaian konflik). ${ }^{33}$ Tenaga medis dan konselor dapat memberikan edukasi pada orangtua untuk membatasi anak bermain gadget, dan tidak perlu melarang anak beraktivitas di luar rumah, selama tidak menyebabkan anak kelelahan.

\section{Kesimpulan}

Proporsi anak epilepsi yang mengalami gangguan perilaku adalah 3 dari 30 subjek. Jenis gangguan perilaku adalah eksternalisasi (melanggar aturan dan agresif), masalah sosial, dan gangguan pemusatan perhatian. Faktor tingkat sosial ekonomi keluarga, tingkat pendidikan orangtua, usia awitan kejang, frekuensi kejang, durasi epilepsi, dan obat anti epilepsi tidak berisiko meningkatkan gangguan perilaku. Keluarga dengan anak epilepsi tanpa gangguan perilaku beradaptasi lebih baik dibandingkan dengan yang mengalami gangguan perilaku.

\section{Daftar pustaka}

1. Shinnar S, Pellock JM. Update on the epidemiology and prognosis of pediatric epilepsy. J Child Neurol 2002;17:S417.

2. Sillanpaa M, Jalava M, Kaleva O, Shinnar S. Long term prognosis of seizure with onset in childhood. $\mathrm{N}$ Engl J Med 1998;338:1715-22.

3. Suwarha IGNM. Insidens dan karakteristik klinis epilepsi pada anak. Sari Pediatri 2011;13:123-8.

4. Saskia GM, van Mil MA, Reijs RP, van Hall MHJA, Snoeijen SM, Aldenkamp AP. Behavioral status of children with cryptogenic localization-related epilepsy. J Child Neurol 2009;24:449-53.

5. Rodenburg R, Stams GJ, Meijer AM, Aldenkamp AP. Dekovic M. Psychopathology in children with epilepsy: a meta-analysis. J Pediatr Psychol 2005;30:453-68.

6. McDermott S, Mani S, Krishnaswami S. A populationbased analysis of specific behavior problems associated 
with childhood seizures. J Epilepsy 1995;8:110-8.

7. Keene DL, Manion I, Whiting S, Belanger E, Brennan R, Jacob P, Humphreys P. A survey of behavior problems in children with epilepsy. Epilepsy Behav 2005;6:581-6.

8. Jones JE. Psychiatric comorbidity in children with new onset epilepsy. Dev Med Child Neurol 2007;49:493-7.

9. Dunn DW. Neuropsychiatric aspects of epilepsy in children. Epilepsy Behav 2003;4:101-6.

10. Austin JK, Dunn DW, Caffrey HM, Perkins SM, Harezlak J, Rose DF. Recurrent seizures and behavioral problems in children with first recognized seizures: a prospective study. Epilepsia 2002;42:1564-73.

11. Freilinger M, Reisel B, Reiter E, Zelenko M, Hauser E, Seidl R. Behavioral and emotional problems in children with epilepsy. J Child Neurol 2006;21:939-45.

12. Prassouli A, Katsarou E, Attilakos A, Sarafidou J, Sotiria $\mathrm{M}$, Voudris K dkk. Behavioral and emotional problems in children with idiopathic epilepsy and well controlled seizures. Pediatrics. 2008;121;S148.

13. Gaitatzis A, Trimble MR, Sander JW. The psychiatric comorbidity of epilepsy. Acta Neurol Scand 2004;110:207-20.

14. Hamiwka LD, Wirrell EC. Comorbidities in pediatric epilepsy: beyond just treating the seizures. J Child Neurol 2009;24:734-42.

15. Pellock JM. The challenge of neuropsychiatric issues in pediatric epilepsy. J Child Neurol. 2004;19:S1-5.

16. Dunn DW, Austin JK, Huster GA. Behavioral problems in children with new onset epilepsy. Seizure 1997;6:2837.

17. Austin JK, Harezlak J, Dunn DW, Huster GA, Rose DF, Ambrosius WT. Behavior problems in children before first recognized seizures. Pediatrics 2001;107:115-22.

18. Oostrom KJ, Smeets-Schouten A, Kruitwagen CLJJ, Peters ACB, Jennekens-Schinkel A. Not only a matter of epilepsy: early problems of cognition and behavior in children with "epilepsy only" a prospective, longitudinal, controlled study starting at diagnosis. Pediatrics 2003; 112:1338-44.

19. Oostrom KJ, Schouten A, Kruitwagen CLJJ, Peters ACB, Jennekens-Schinkel A. Behavioral problems in children with newly diagnosed idiopathic or cryptogenic epilepsy attending normal schools are in majority not persistent. Epilepsia 2003;44:97-106.

20. De Boer HM, Mula M, Sander JW. The global burden and stigma of epilepsy. Epilepsy Behav 2008;12:540-6.
21. Achenbach TM. The child behavior checklist and related forms for assessing behavioral/emotional problems and competencies. Pediatr Rev 2000;21:265-71.

22. Austin JK, Dunn DW, Johnson CS, Perkins SM. Behavioral issue involving children and adolescent with epilepsy and the impact of their families: recent research data. Epilepsy Behav 2004;5:33-41

23. Buelow JM. An intervention for parents of children with epilepsy and significant learning problems: lessons learned from a feasibility study. J Am Psychiatr Nurses Assoc 2007;13:146-52.

24. Ziegler RG, Erba G, Holden L, Dennison H. The coordinated psychosocial and neurological care of children with seizures and their families. Epilepsia 2000;41:732-43.

25. Oostrom KJ, Smeets-Schouten A, Kruitwagen CLJJ, Peters ACB, Jennekens-Schinkel A. Parents' perceptions of adversity introduced by upheavel and uncertainty at the onset of childhood epilepsy. A prospective, controlled study. Epilepsia 2001;42:1452-60.

26. Grosso S, Cordelli DM, Franzoni E, Coppola G, Capovilla G, Zamponi N, dkk. Efficacy and safety of levetiracetam in infants and young children with refractory epilepsy. Seizure 2007;16:345-50.

27. Mitchell WG, Scheier LM, Baker SA. Psychosocial, behavioral, and medical outcomes in children with epilepsy: a developmental risk factor model using longitudinal data. Pediatrics 1994;94:471-7.

28. Jayashree K, Talukdar B, Srivastava PK, Sharma U. Cognitive function and behavior in epileptic children of school going age. Indian Pediatr 1999;36:1032-8.

29. Datta SS, Premkumar TS. Behavior problems in children and adolescent with seizure disorder: association and risk factors. Seizure 2005;14:190-7.

30. Bourgeis BFD. Antiepileptic drugs, learning and behavior in childhood epilepsy. Epilepsia 1998;39:913-21.

31. Bourgeis BFD. Determining the effects of antiepileptic drugs on cognitive function in pediatric patient with epilepsy. J Child Neurol 2004;19:S15-24.

32. Pope C, Mays N. Reaching the parts other methods can not reach: an introduction of qualitative methods in health and health services research.BMJ 1995;311:425.

33. The British Psychological Society. Gadgets affect child development. Diakses pada 14 Mei 2014. Diunduh dari http://www.bps.org.uk/news/gadgets-affect-child-development. 